\title{
Nonadditive effects of biochar amendments on soil phosphorus fractions in two contrasting soils
}

\author{
Gang $\mathrm{Xu}^{1}$ | Hongbo Shao ${ }^{2,3}$ (D) | You Zhang ${ }^{1,5}$ | Sun Junna ${ }^{4}$
}

${ }^{1}$ Yantai Institute of Coastal Zone Research, Chinese Academy of Sciences, Yantai 264003, PR, China

${ }^{2}$ Salt-soil Agricultural Center, Institute of Agricultural Resources and Environment, Jiangsu Academy of Agricultural Sciences, Nanjing 210014, Jiangsu, PR, China

${ }^{3}$ Jiangsu Key Laboratory for Bioresources of Saline Soils, Jiangsu Synthetic Innovation Center for Coastal Bio-agriculture, Yancheng Teachers University, Yancheng 224002, PR, China

${ }^{4}$ School of Life Science, Ludong University, Yantai 264025, PR, China

${ }^{5}$ University of Chinese Academy of Sciences, Beijing 100049, PR, China

Correspondence

Hongbo Shao, Salt-soil Agricultural Center, Institute of Agricultural Resources and Environment, Jiangsu Academy of Agricultural Sciences, Nanjing, 210014, Jiangsu, PR China. Email: shaohongbochu@126.com

\section{Funding information}

Shuangchuang Talent Plan of Jiangsu Province, China; Agricultural Independent Innovation of Jiangsu Province, Grant/Award Number: CX (15)1005; National Natural Science Foundation of China, Grant/Award Numbers: 41501309 and 41573120; the Key Deployment Project of Chinese Academy of Sciences, Grant/Award Number: (KFZD-SW-112); the Science and Technology Service Network Initiative, Grant/Award Number: (KFJ-STSZDTP-023)

\begin{abstract}
Increased soil total phosphorus $(\mathrm{P})$ or available $\mathrm{P}$ has been reported in biocharamended soils, although the underlying mechanisms need to be fully understood. In the present study, two contrasting soils (acidic Haplic Luvisol and alkaline CalcaricFluvisol) amended with wheat straw biochar were sequentially extracted with modified Hedley method to study the P transformation in the soils. Our results showed that biochar application significantly increased (positive effects) $\mathrm{P}$ fractions (except for $\mathrm{NaHCO}_{3}-\mathrm{P}_{\mathrm{i}}$ and residual-P) content in Haplic Luvisol. The increased soil microbial activity and reduced soil acidity or increased cation exchange capacity may be accounted for enhanced $\mathrm{P}$ transformation. The reduced $\mathrm{NaHCO}_{3}-\mathrm{P}_{\mathrm{i}}$ content may be related to $\mathrm{P}$ immobilization with increased soil microbial activity induced by biochar addition because the high C:P ratios of biochar (ranged from 234 to 357 ) suggested net $\mathrm{P}$ immobilization occurred when biochar was incorporated into soil. Biochar application first (4 days) increased soil $\mathrm{NaHCO}_{3}-\mathrm{P}_{\mathrm{o}}$ content and then decreased it with longer incubation time (30 days). The decrease in $\mathrm{NaHCO}_{3}-\mathrm{P}_{\mathrm{o}}$ suggested that the labile organic $\mathrm{P}$ was converted into nonlabile inorganic or organic $\mathrm{P}$. In comparison with those in Haplic Luvisol, almost all P fractions showed negative effects with biochar addition into Calcaric-Fluvisol. The results may be caused by the $\mathrm{P}$ precipitation or sorption with increased soil $\mathrm{pH}$ with biochar application. On the basis of $\mathrm{P}$ transformation, biochar is recommended to be used in Haplic Luvisol (acidic soil) and not to Calcaric-Fluvisol (alkaline soil) because of the positive effects and negative effects observed on $\mathrm{P}$ fractions in biochar-amended soils.
\end{abstract}

\section{KEYWORDS}

biochar, Calcaric-Fluvisol, Haplic Luvisol, Hedley fraction, transformation

\section{1 | INTRODUCTION}

Biochar is a solid material obtained from thermochemical conversion of biomass in an oxygen-limited environment. Biochar addition into soil has been proved to sequester carbon (C) in soil, to increase soil water holding capability, to improve soil fertility and decrease soil nutrient leaching loss (Guo, He, \& Uchimiya, 2016; Jeffery et al., 2017; Schulz \& Glaser, 2012; Singh, Singh, \& Cowie, 2010), and to immobilize contaminants in soil (Ahmad et al., 2014). Indeed, decrease of soil fertility and crop productivity due to soil degradation around the world has been increasingly recognized as a global challenge for food security especially for the agricultural China (Smith \& Gregory, 2013). Considering the importance of enhancing soil fertility and productivity, biochar's role in addressing soil productivity is clearly critical, and studies had shown that biochar application increased soil productivity and plant yield (Biederman \& Harpole, 2013). Biochar can improve soil fertility through its beneficial effects on phosphorus $(P)$ availability. Phosphorus $(\mathrm{P})$ is an essential element for plant growth. However, excess $\mathrm{P}$ input can cause $\mathrm{P}$ accumulation in farmland soil. This $P$ in the soil can be easily leached out due to surface runoff or lost 
through erosion, and then it enters water bodies, causing eutrophication and damage to the environment (Elser \& Bennett, 2011). There are increasing evidences indicating that biochar application can increase $\mathrm{P}$ content and therefore enhance $\mathrm{P}$ availability and promote plant growth (Biederman \& Harpole, 2013; Singh et al., 2015) whereas it can also reduce $\mathrm{P}$ leaching from amended soils.

Biochar is reported to improve soil physical, chemical, and biological properties and therefore affect the amount of $\mathrm{P}$ used by plant (Scott, Ponsonby, \& Atkinson, 2014). Biochar is considered an important source of $\mathrm{P}$ (generally present in the inorganic form) because most of the $\mathrm{P}$ from feedstock is retained into biochar during the pyrolysis process (Kloss et al., 2012). As a result, the $P$ in biochar can be released and directly used by plant. Biochar can also improve the availability of soil $\mathrm{P}$ by increasing soil $\mathrm{pH}$ and cation exchange capacity (CEC). Changes in soil $\mathrm{pH}$ values also affect $\mathrm{P}$ adsorption and desorption (Parvage, Ulén, Eriksson, Strock, \& Kirchmann, 2013). In acidic soil, biochar application increased soil $\mathrm{pH}$ and thereby increased the availability of nutrients in the soil (particularly P; Novak et al., 2009). Biochar application alters $\mathrm{P}$ availability by changing $\mathrm{P}$ sorption and desorption capacities of soils (Zhang et al., 2016). Biochar addition reduced the amount of exchanged iron and aluminum and increased the availability of P (DeLuca, MD, \& Gundale, 2009; Mao et al., 2016; Xu, Wei, Sun, Shao, \& Chang, 2013). Makoto et al. (2012) found that the charcoal left over from forest fires might adsorb soil $P$ through its numerous pores, inhibiting $\mathrm{P}$ loss and extending $\mathrm{P}$ retention time. Also, Morales, Comerford, Guerrini, Falcão, and Reeves (2013) referred that the effect of biochar on soil P adsorption depends on the characteristics of the biochar. The authors reported that when P-rich biochar is applied to soils, P tends to be adsorbed. Biochar application significantly increased the Ca-bound $\mathrm{P}$ and slightly enhanced the Al-retained $\mathrm{P}$ but decreased the Fe-bound $\mathrm{P}$ in soil, suggesting that the increase in $\mathrm{P}$ sorption with biochar addition is attributed to Ca-induced $\mathrm{P}$ sorption or precipitation and is less affected by Fe and Al oxides (Xu, Wei, Sun, Shao, \& Chang, 2013; Zhang et al., 2016). The effects of biochar on soil microbial biomass, community composition, and microbial activity are summarized in a metaanalysis of 371 independent studies (Biederman \& Harpole, 2013). They generally found a significant increase of soil microbial biomass with biochar application. Anderson et al. (2011) reported that biochar could improve the availability in soil $\mathrm{P}$ by enhancing soil microbial activity.
In general, these studies have highlighted the increase of the total or available P content in biochar-amended soils, but there is still a lack of understanding of $\mathrm{P}$ transformations. In this study, two soils defined as Haplic Luvisol (acidic soil) and Calcaric-Fluvisol (alkaline soil) amended with biochar were sequentially extracted by the modified Hedley method (Tiessen \& Moir, 1993). The transformation of soil $P$ was calculated on the basis of $\mathrm{P}$ fractions in biochar and biocharamended soils. These results provide a reference for biochar production and the further use of biochar in agricultural field.

\section{2 | MATERIALS AND METHODS}

\section{1 | Soils and biochars}

The acidic soil $(\mathrm{pH}=4.7)$ was collected from orchards in Yantai, China. The soil type was Haplic Luvisol (World Reference Base), and the organic matter content was $32 \mathrm{mg} \mathrm{g}^{-1}$. The alkaline soil $(\mathrm{pH}=8.3)$ was a Calcaric-Fluvisol (World Reference Bas) collected from a Suaeda salsa field in Yellow River Delta, China. The soil type was a sand-based soil with an organic matter content of $8 \mathrm{mg} \mathrm{g}^{-1}$. Fresh surface soil samples were collected $(0-20 \mathrm{~cm})$; gravel, grass roots, and other impurities were removed; and the samples were passed through a 2-mm sieve for future use.

Washed and dried fresh wheat straw was selected as the raw material and charred using a muffle furnace in the absence of oxygen for $4 \mathrm{hr}$. The temperature was set to $300^{\circ} \mathrm{C}, 400^{\circ} \mathrm{C}, 500^{\circ} \mathrm{C}$, and $600^{\circ} \mathrm{C}$, respectively (Xu, Zhang, Shao, \& Sun, 2016). After being charred, the samples were allowed to cool to room temperature, passed through a 2-mm sieve, and packaged in bags for future use. The biochars pyrolyzed at the different temperatures were referred to as WB300, WB400, WB500, and WB600, respectively.

Details of the forms of $\mathrm{P}$ in the biochars are given in previous literature (Xu, Zhang, Shao, \& Sun, 2016). The $\mathrm{pH}$ was determined with a glass electrode with 1:2.5 (1:20 for biochar) soil to water ratio. Electrical conductivity was determined by a DDS-307 conductivity meter (Shanghai Precision Scientific Instrument Ltd., China) with 1:5 (1:20 for biochar) soil to water ratio. CEC was measured by sodium acetate flame atomic absorption spectrophotometer. Ash content was measured by ignition method. Total organic $\mathrm{C}$ and total $\mathrm{N}$ were determined by combustion on a LECO CNS-2000 elemental analyzer.

TABLE 1 The physical and chemical properties of the studied soils and biochars (soil classification according to World Reference Base; Shi et al., 2010)

\begin{tabular}{|c|c|c|c|c|c|c|c|c|c|c|c|c|}
\hline & Ash & CEC & EC & & Sand & Slit & clay & Total N & Total P & Organic C & $\mathrm{C}: \mathrm{N}$ & $C: P$ \\
\hline Soil/biochar & $\%$ & $\mathrm{cmol} \mathrm{kg}^{-1}$ & $\mu \mathrm{sm}^{-1}$ & $\left(\mathrm{H}_{2} \mathrm{O}\right)$ & $\mathrm{g} \mathrm{kg}^{-1}$ & & & & & & & \\
\hline Haplic Luvisol & - & 6 & 357 & 4.7 & 512 & 451 & 37 & 2.4 & 1.4 & 28 & 12 & 20 \\
\hline W & 6.1 & - & - & 5.6 & - & - & - & 17.0 & 5.7 & 375 & 22 & 341 \\
\hline WB300 & 10.1 & 286 & 3,975 & 6.8 & - & - & - & 14.8 & 10.3 & 643 & 43 & 357 \\
\hline WB600 & 19.6 & 148 & 6,495 & 10.3 & - & - & - & 10.0 & 11.5 & 702 & 70 & 234 \\
\hline
\end{tabular}

Note. WB300, WB400, WB500, and WB600 are wheat straw biochars pyrolyzed at $300^{\circ} \mathrm{C}, 400^{\circ} \mathrm{C}, 500^{\circ} \mathrm{C}$, and $600^{\circ} \mathrm{C}$, respectively. $-:$ not determined; $\mathrm{W}$ : wheat straw; CEC: cation exchange capacity; EC: electrical conductivity. 
Grain-size distributions in the soil samples were determined using a Mastersizer 2000 Laser Grain size analyzer (Malvern Instruments Ltd., UK). The detailed properties of soils and biochars are described in Table 1.

\subsection{Soil incubation experiment and $\mathrm{P}$ analysis}

Wheat straw or biochar equivalent to $20 \mathrm{mg}$ of $\mathrm{P}$ (equivalent to $125 \mathrm{~kg}$ $\mathrm{P} \cdot \mathrm{ha}^{-1}$ ) was added to 200-g fresh Haplic Luvisol and Calcaric-Fluvisol. The samples were placed in an incubator at $25^{\circ} \mathrm{C}$, the soil moisture content was set to $70 \%$ of the maximum soil water holding capacity, and the soil incubation experiment was performed for 30 days (the highest demand for $\mathrm{P}$ of crops occurs in the first 30 days during the early stage; Alamgir \& Marschner, 2013). Three replicates of each treatment were considered. Subsamples were collected on Days 3 and 30 and air-dried for future use. The soil samples amended with biochar pyrolyzed at the different temperatures were defined as WS300, WS400, WS500, and WS600, respectively. The raw material was referred to as WS, and a control treatment was also established.

A modified sequential Hedley fractionation was used to extract $P$ in soils (Tiessen \& Moir, 1993). Generally, soils were extracted step by step using deionized water (18.2 $\mathrm{M} \Omega$ ), $0.5 \mathrm{M} \mathrm{NaHCO}_{3}, 0.1 \mathrm{M} \mathrm{NaOH}$, and $1 \mathrm{M} \mathrm{HCl}$. Shaking time for each fraction was $16 \mathrm{hr}$. The $\mathrm{NaHCO}_{3}$ and $\mathrm{NaOH}$ extracts were divided into two aliquots in order to measure the total $\mathrm{P}$ and inorganic $\mathrm{P}$. Organic $\mathrm{P}$ was calculated as a difference between total $P$ and inorganic $P$. Inorganic $P$ and total $P$ (digested with $\mathrm{K}_{2} \mathrm{~S}_{2} \mathrm{O}_{8} / \mathrm{H}_{2} \mathrm{SO}_{4}$ at $130^{\circ} \mathrm{C}$ ) were determined by a Tu-1810 spectrophotometer (PERSEE, China), using the ascorbic acid molybdenum blue method (Murphy \& Riley, 1962). Residual-P, the remaining P in the soil after all the above extractions, was measured after $\mathrm{H}_{2} \mathrm{SO}_{4} / \mathrm{H}_{2} \mathrm{O}_{2}$ digestion at $360^{\circ} \mathrm{C}$.

\section{3 | Data calculation and analysis}

The differences of $\mathrm{P}$ fractions from analyzed and predicted, here attributed to the added biochar, are represented using transformation, and the equation used for this calculation is as follows (Wang, Fang, Chang, \& Tian, 2014):

Transformation $(\%)=100 \times\left(P_{\text {analyzed }}-P_{\text {predicted }}\right) / P_{\text {predicted }}$,

$$
P_{\text {predicted }}=P_{\text {biochar }} \times f+P_{\text {soil }} \times(1-f) .
$$

In the equations, $P_{\text {analyzed }}$ represents the measured value of one form of $P$ in biochar-treated soil. $P_{\text {predicted }}$ is the theoretical value of one form of $\mathrm{P}$ in soil $\left(P_{\text {soil }}\right)$ and in biochar $\left(P_{\text {biochar }}\right.$; Equation 2$) . f$ is the mass percentage of the biochar added to the soil $(\mathrm{w} / \mathrm{w})$.

Here, transformation represents the interaction between soil and biochar. A positive value indicates that the concentration of one form of $\mathrm{P}$ in biochar-amended soil is greater than the sum of the concentration of the same form of $\mathrm{P}$ in biochar and soil. However, a negative value indicates that the content of one $\mathrm{P}$ form in biochar-amended soil is lower than the sum of the contents of the same form of $\mathrm{P}$ in biochar and soil.

Microsoft Excel 2010 was used for data analysis and figure production. Significant difference test was performed using SPSS computer package (SPSS Inc., Chicago, USA, 1999) for all data sets, and the differences between means $(n=3)$ were considered statistically significant at $P<0.05$.

\section{3 | RESULTS}

\section{1 | Changes of $\mathbf{P}$ fractions induced by biochar addition into a Haplic Luvisol}

As shown in Table 2, on Day 4, the Haplic Luvisol showed slightly more soluble $\mathrm{P}\left(\mathrm{H}_{2} \mathrm{O}-\mathrm{P}_{\mathrm{i}}\right)$ than the control sample did, but the difference was not significant except for that of WS400. The $\mathrm{NaHCO}_{3}-\mathrm{P}$ content was significantly lower than that of the control, and the $\mathrm{NaHCO}_{3}-\mathrm{P}_{\mathrm{O}}$ content in the biochar-treated soil was greater than in the control, and a lower charring temperature led to a higher magnitude of increase. The addition of biochar increased the concentration

TABLE 2 The P fractions (means $\pm S D$ ) in Haplic Luvisol with biochar amendments at Days 4 and 30

\begin{tabular}{|c|c|c|c|c|c|c|c|}
\hline Soil/biochar & $\mathrm{H}_{2} \mathrm{O}-\mathrm{P}_{\mathrm{i}}$ & $\mathrm{NaHCO}_{3}-\mathrm{P}_{\mathrm{i}}$ & $\mathrm{NaHCO}_{3}-\mathrm{P}_{\mathrm{o}}$ & $\mathrm{NaOH}-\mathrm{P}_{\mathrm{i}}$ & $\mathrm{NaOH}-\mathrm{P}_{\mathrm{o}}$ & $\mathrm{HCl}-\mathrm{P}_{\mathrm{i}}$ & Residual-P \\
\hline \multicolumn{8}{|c|}{ Day $4\left(\mathrm{mg} \mathrm{kg}^{-1}\right)$} \\
\hline CK & $109 \pm 4 a$ & $266 \pm 5 d$ & $220 \pm 28_{b, c}$ & $255 \pm 6 a$ & $89 \pm 27 a$ & $190 \pm 17_{a}$ & $221 \pm 31_{c}$ \\
\hline WS300 & $118 \pm 12_{a, b, c}$ & $136 \pm 13 a$ & $460 \pm 15_{e}$ & $293 \pm 15_{b}$ & $107 \pm 36_{a, b}$ & $216 \pm 3_{a, b, c}$ & $90 \pm 15 a$ \\
\hline WS400 & $130 \pm 0_{d}$ & $131 \pm 13_{a}$ & $323 \pm 0_{d}$ & $304 \pm 14_{b}$ & $128 \pm 0_{a, b}$ & $252 \pm 2_{e}$ & $107 \pm 21_{b}$ \\
\hline \multicolumn{8}{|c|}{ Day $30\left(\mathrm{mg} \mathrm{kg}^{-1}\right)$} \\
\hline CK & $160 \pm 2 \mathrm{e}$ & $244 \pm 14_{c}$ & $166 \pm 10_{\mathrm{a}, \mathrm{b}}$ & $366 \pm 9 c$ & $116 \pm 18_{a, b}$ & $218 \pm 13_{b, c}$ & $180 \pm 14_{b}$ \\
\hline WS & $131 \pm 3_{a, b, c, d}$ & $199 \pm 8_{b}$ & $173 \pm 25_{\mathrm{a}, \mathrm{b}}$ & $373 \pm 19_{c}$ & $117 \pm 36_{a, b}$ & $224 \pm 17_{b, c, d}$ & $123 \pm 24_{b}$ \\
\hline WS300 & $154 \pm 5_{\mathrm{d}, \mathrm{e}}$ & $236 \pm 9_{c}$ & $100 \pm 27 a$ & $443 \pm 24_{d}$ & $109 \pm 48_{a, b}$ & $204 \pm 12_{a, b}$ & $115 \pm 19_{b}$ \\
\hline
\end{tabular}

Note. WS300, WS400, WS500, and WS600 are amended soils with WB300, WB400, WB500, and WB600 biochars, respectively. WS: wheat straw amended soil; CK: control. Different letters in the same column indicate the significance level at $P<0.05$. 
of $\mathrm{NaOH}-\mathrm{P}_{\mathrm{i}}$ in soil, but no significant changes were observed in the wheat straw-treated samples and in the WS600 treatment. As with $\mathrm{NaOH}-\mathrm{P}_{\mathrm{o}}$, although biochar application increased the soil $\mathrm{NaOH}-\mathrm{P}_{\mathrm{o}}$, only wheat straw treatment revealed significant differences. Soil $\mathrm{HCl}-\mathrm{P}_{\mathrm{i}}$ content tended to increase after the addition of biochar. The residual-P followed decreasing trend with biochar application over incubation time.

The variation of $\mathrm{P}$ fractions followed generally the same trends at 30 days of incubation, except for $\mathrm{NaHCO}_{3}-\mathrm{P}_{\mathrm{i}}$ and $\mathrm{NaHCO}_{3}-\mathrm{P}_{\mathrm{o}}$. The concentrations of soil $\mathrm{H}_{2} \mathrm{O}-\mathrm{P}_{\mathrm{i}}, \mathrm{NaOH}-\mathrm{P}_{\mathrm{i}}$, and $\mathrm{NaOH}-\mathrm{P}_{\mathrm{o}}$ exhibited an upward trend with increasing incubation time. However, the concentration of $\mathrm{NaHCO}_{3}-\mathrm{P}_{\mathrm{O}}$ displayed a significant decrease with incubation time, and the magnitude of the decline in the biochar-treated sample was significantly lower than in the control. The corresponding $\mathrm{NaHCO}_{3}-\mathrm{P}_{\mathrm{i}}$ concentration in the biochar-treated sample was significantly higher. The $\mathrm{HCl}-\mathrm{P}_{\mathrm{i}}$ content did not change significantly over time.

\subsection{Changes of $\mathbf{P}$ fractions induced by biochar addition into a Calcaric-Fluvisol}

As shown in Table 3, on Day 4 of the amendment, the content of $\mathrm{H}_{2} \mathrm{O}$ $\mathrm{P}_{\mathrm{i}}$ showed no significant differences between treatments, except for that with the WS600 treatment that registered a significantly higher amount of $\mathrm{H}_{2} \mathrm{O}$-extracted $\mathrm{P}$. The $\mathrm{NaHCO}_{3}-\mathrm{P}_{\mathrm{i}}$ and $\mathrm{NaHCO}_{3}-\mathrm{P}_{\mathrm{o}}$ did not present significant differences among most treatments, despite the distinct tendencies with the biochar addition, that is, an increase in $\mathrm{NaHCO}_{3}-\mathrm{Pi}$ and a decrease in $\mathrm{NaHCO}_{3}-\mathrm{P}_{\mathrm{o}}$. At the same time, biochar application did not significantly increase the content of $\mathrm{NaOH}$ $\mathrm{P}_{\mathrm{i}}$ and $\mathrm{NaOH}-\mathrm{P}_{\mathrm{o}}$, as well as the concentration of $\mathrm{HCl}-\mathrm{P}_{\mathrm{i}}$ and residual$P$ in most treatments.

On the 30th day of amendment, the concentrations of $\mathrm{H}_{2} \mathrm{O}-\mathrm{P}_{\mathrm{i}}$ and $\mathrm{NaHCO}_{3}-\mathrm{P}_{\mathrm{i}}$ in biochar-treated soil were significantly higher than those of the control, and this trend became more apparent with increasing pyrolyzed temperature biochar. The effect of biochar on $\mathrm{NaHCO}_{3}-\mathrm{P}_{\mathrm{o}}$ was not significant. Addition of biochar did not significantly affect soil
$\mathrm{NaOH}-\mathrm{P}_{\mathrm{i}}$ content, whereas it significantly reduced the $\mathrm{NaOH}-\mathrm{P}_{\mathrm{o}}$ concentration. The concentrations of $\mathrm{HCl}-\mathrm{P}_{\mathrm{i}}$ and residual-P were not significantly affected with biochar incorporation, although lower temperature produced biochar seemed to increase $\mathrm{HCl}-\mathrm{P}_{\mathrm{i}}$ content.

From Day 4 to Day 30 of amendment, the concentrations of $\mathrm{H}_{2} \mathrm{O}$ $\mathrm{P}_{\mathrm{i}}$ and $\mathrm{NaOH}-\mathrm{P}_{\mathrm{o}}$ were significantly enhanced with biochar application. At the same time, biochar seemed to have little effect on $\mathrm{NaHCO}_{3}-\mathrm{P}$, $\mathrm{NaHCO}_{3}-\mathrm{P}_{\mathrm{o}}, \mathrm{NaOH}-\mathrm{P}_{\mathrm{i}}, \mathrm{HCl}-\mathrm{P}_{\mathrm{i}}$, and residual- $\mathrm{P}$, although higher temperature produced biochar tended to increase $\mathrm{NaHCO}_{3}-\mathrm{P}_{\mathrm{i}}$ and $\mathrm{NaHCO}_{3}-\mathrm{P}_{\mathrm{O}}$ content.

\section{4 | DISCUSSION}

\subsection{P transformation induced by biochar addition in a Haplic Luvisol}

As shown in Figure 1, on Day 4 after the biochar was added to the Haplic Luvisol, biochar addition significantly increased various forms of $\mathrm{P}$ (except $\mathrm{NaHCO}_{3}-\mathrm{P}_{\mathrm{i}}$ and residual-P), indicating a positive effect on these $\mathrm{P}$ fractions. This promoting effect occurring between biochar and soil led to the increase of soil P. It is considered that biochar affects soil $\mathrm{P}$ transformations in a number of ways. First, biochar contains large amounts of $P$, which may be released into soils, increasing the content of soil P (Angst \& Sohi, 2013). However, the P in the biochar did not affect the transformation of soil $\mathrm{P}$, although it increased available $\mathrm{P}$ content in amended soil. Second, incorporation of the biochar reduced soil acidity and increased soil CEC (Liang et al., 2006); thus, soil surface became more negatively charged and increased anion repulsion and subsequently decreased the $\mathrm{P}$ adsorption by the soils (Murphy \& Stevens, 2010). The Haplic Luvisol showed increases in $\mathrm{pH}$ and $\mathrm{CEC}$ with biochar application (Table 1), so $\mathrm{P}$ desorption may have been responsible for increasing $\mathrm{P}$ solubility (e.g., $\mathrm{H}_{2} \mathrm{O}-\mathrm{P}_{\mathrm{i}}$ ) in the soils (Jiang, Yuan, Xu, \& Bish, 2015). Third, biochar application changed the form of $\mathrm{Fe}, \mathrm{Al}, \mathrm{Ca}$, and other agents of $\mathrm{P}$ adsorption (fixation), all of which significantly influenced soil $\mathrm{P}$ transformation

TABLE 3 The P fractions (means $\pm S D$ ) in Calcaric-Fluvisol with biochar amendments at Days 4 and 30

\begin{tabular}{|c|c|c|c|c|c|c|c|}
\hline Soil/biochar & $\mathrm{H}_{2} \mathrm{O}-\mathrm{P}_{\mathrm{i}}$ & $\mathrm{NaHCO}_{3}-\mathrm{P}_{\mathrm{i}}$ & $\mathrm{NaHCO}_{3}-\mathrm{P}_{\mathrm{o}}$ & $\mathrm{NaOH}-\mathrm{P}_{\mathrm{i}}$ & $\mathrm{NaOH}-\mathrm{P}_{\mathrm{o}}$ & $\mathrm{HCl}-\mathrm{P}_{\mathrm{i}}$ & Residual-P \\
\hline \multicolumn{8}{|c|}{ Day $4\left(\mathrm{mg} \mathrm{kg}^{-1}\right)$} \\
\hline CK & $1.1 \pm 0.1_{a}$ & $22.0 \pm 0.7_{a, b}$ & $38.3 \pm 7.1_{b, c, d}$ & $6.7 \pm 0.8_{\mathrm{a}, \mathrm{b}}$ & $13.4 \pm 7.0_{a}$ & $483.6 \pm 18.9_{a, b, c}$ & $260.3 \pm 18.5 a$ \\
\hline WS300 & $1.6 \pm 1.2 \mathrm{a}$ & $34.4 \pm 18_{c}$ & $29.0 \pm 8.7_{b}$ & $8.9 \pm 1.4_{b}$ & $18.3 \pm 1.2_{a}$ & $493.4 \pm 5.6_{b, c}$ & $262.1 \pm 21.4$ \\
\hline WS400 & $3.9 \pm 0.1_{a, b}$ & $29.0 \pm 1.2_{\mathrm{a}, \mathrm{b}, \mathrm{c}}$ & $28.0 \pm 2.4_{b}$ & $6.7 \pm 0.8_{a, b}$ & $20.7 \pm 13.4_{\mathrm{a}, \mathrm{b}}$ & $506.7 \pm 28.6_{b, c}$ & $263.2 \pm 16.5 a$ \\
\hline \multicolumn{8}{|c|}{ Day $30\left(\mathrm{mg} \mathrm{kg}^{-1}\right)$} \\
\hline CK & $2.0 \pm 1.0_{a}$ & $21.3 \pm 2.6_{a, b}$ & $39.8 \pm 6.5_{\mathrm{b}, \mathrm{c}, \mathrm{d}, \mathrm{e}}$ & $7.3 \pm 5.7_{\mathrm{a}, \mathrm{b}}$ & $48.8 \pm 19.0_{d}$ & $448.2 \pm 53.8 \mathrm{a}$ & $257.2 \pm 22.6_{a}$ \\
\hline WS & $5.4 \pm 0.5_{\mathrm{a}, \mathrm{b}}$ & $19.8 \pm 0.7 a$ & $34.8 \pm 3.3_{\mathrm{b}, \mathrm{c}}$ & $7.3 \pm 1.3_{\mathrm{a}, \mathrm{b}}$ & $39.5 \pm 4.2_{c, d}$ & $470.3 \pm 22.2_{a, b}$ & $258.8 \pm 33.4 a$ \\
\hline WS300 & $5.5 \pm 0.2_{a, b}$ & $26.6 \pm 2.7_{\mathrm{a}, \mathrm{b}, \mathrm{c}}$ & $40.3 \pm 13.3_{\mathrm{b}, \mathrm{c}, \mathrm{d}, \mathrm{e}}$ & $8.5 \pm 1.8_{b}$ & $32.9 \pm 4.4_{b, c}$ & $488.6 \pm 12.0_{b, c}$ & $245.1 \pm 12.9$ \\
\hline
\end{tabular}

Note. WS300, WS400, WS500, and WS600 are amended soils with WB300, WB400, WB500, and WB600 biochars, respectively. WS: wheat straw amended soil; CK, control. Different letters in the same column indicate the significance level at $P<0.05$. 


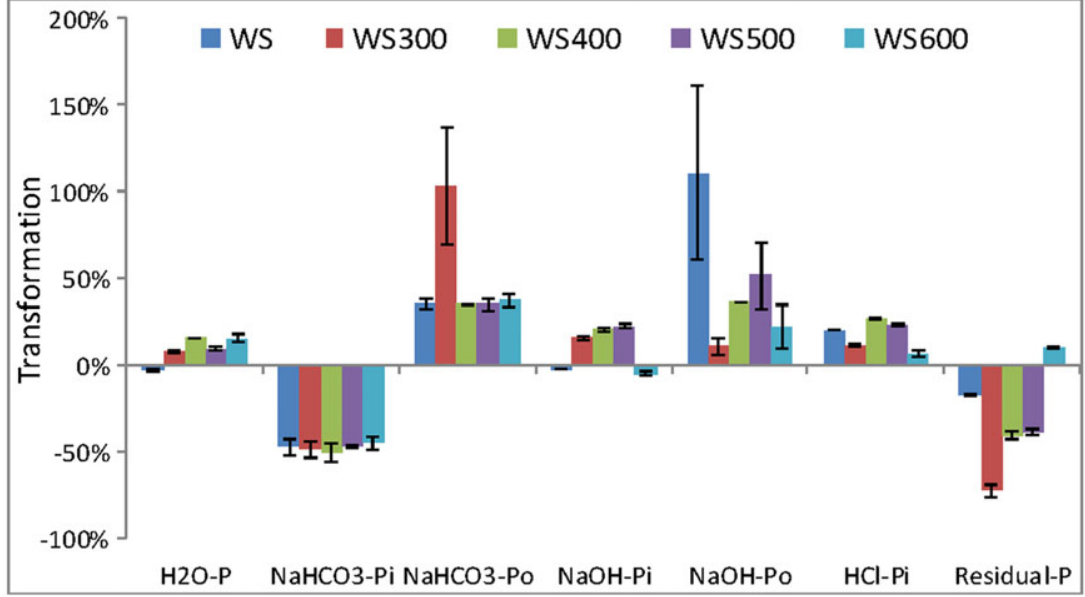

FIGURE 1 The transformations of $\mathrm{P}$ in a Haplic Luvisol at four incubation days with different biochars (data in the figure indicate means of three replicates, $\pm S D$ ) [Colour figure can be viewed at wileyonlinelibrary.com]
(Parvage, Ulén, Eriksson, Strock, \& Kirchmann, 2013; Srivastava, Gupta, Shikha, \& Tewari, 2016; Xu, Wei, Sun, Shao, \& Chang, 2013). However, the previous studies indicated that biochar containing moderate $\mathrm{Ca}^{2+}$ and $\mathrm{Mg}^{2+}$ formed precipitates with phosphate in the soils and increases the phosphorus adsorption (Jiang, Yuan, $\mathrm{Xu}, \&$ Bish, 2015). These results were agreement with our findings in which biochar application increased $\mathrm{P}$ sorption and decreased $\mathrm{P}$ availability in acidic soil due to chemical retardation of $\mathrm{Ca}^{2+}$ and $\mathrm{Mg}^{2+}$ (Xu, Sun, Shao, \& Chang, 2014). As a result, the transformation of $P$ fractions in Haplic Luvisol cannot be explained by the variations of $\mathrm{P}$ adsorption agents (such as $\mathrm{Fe}, \mathrm{Al}$, and $\mathrm{Ca}$ ) with biochar application.

Finally, biochar may affect $P$ availability in the soil through changes in microbial metabolism and diversity (Hammer et al., 2014; Zhai et al., 2014). Microbial activity was reported as a central factor in the soil organic $\mathrm{P}$ cycle and also affects the transformations of inorganic $P$ (Hammer et al., 2014). The highly porous nature of biochar and its high internal reliable organic matter and inorganic nutrients are likely to provide a favorable habitat for microorganisms. The increased content of $\mathrm{NaHCO}_{3}-\mathrm{P}_{\mathrm{O}}$ and $\mathrm{NaOH}-\mathrm{P}_{\mathrm{O}}$ indicated that biochar application increased microbial activity and thereby stimulated the buildup of organic $P$ forms at early soil incubation stage (Day 4; DeLuca, $\mathrm{MD}, \&$ Gundale, 2009). The bicarbonate-extracted $\mathrm{P}\left(\mathrm{NaHCO}_{3}-\mathrm{P}\right)$ is available $\mathrm{P}$, and it can be directly absorbed by plants and microbes ( $\mathrm{He}$, Qian, Liu, Jiang, \& Yu, 2014). The reduced $\mathrm{NaHCO}_{3}-\mathrm{P}_{\mathrm{i}}$ may also be related to changes of microbial activity with biochar application.
Zhai et al. (2014) reported that biochar addition significantly increased soil microbial biomass $\mathrm{P}$ in short-term incubation time. The increased microbial activity inevitably absorbed more reactive inorganic $\mathrm{P}$, resulting in a reduced concentration of $\mathrm{NaHCO}_{3}-\mathrm{P}_{\mathrm{i}}$ (Vanek \& Lehmann, 2015; Zhai et al., 2014). This may be explained by the C:P ratio of biochar that ranged between 234 and 357 (Table 1), a value well above the threshold (100) of $\mathrm{P}$ immobilization, resulting therefore in the decrease in $\mathrm{NaHCO}_{3}-\mathrm{P}_{\mathrm{i}}$. The obtained results were in agreement with Alamgir et al. (2012) who reported that low $P$ legume residue decreased soil $\mathrm{NaHCO}_{3}-\mathrm{P}_{\mathrm{i}}$ content whereas it increased soil microbial activity due to $\mathrm{P}$ immobilization in a short-term incubation (<14 days). Due to no $\mathrm{HCl}-\mathrm{P}_{\mathrm{o}}$ measurement, there was a possibility of some $\mathrm{P}_{\mathrm{o}}$ present in the $\mathrm{HCl}$ fraction and not accounted for as in some cases demonstrated by He et al. (2006).

The positive effect of biochar on $\mathrm{H}_{2} \mathrm{O}-\mathrm{P}_{\mathrm{i}}$ and $\mathrm{NaOH}-\mathrm{P}_{\mathrm{i}}$ became stronger with longer incubation time, and the negative effect of biochar on $\mathrm{NaHCO}_{3}-\mathrm{P}_{\mathrm{i}}$ became less apparent (Figure 2), indicating that adding biochar favors the generation of these forms of $\mathrm{P}$ (Farrell, Macdonald, Butler, Chirino-Valle, \& Condron, 2014). From Day 4 to Day 30 of amendment, the positive effect of $\mathrm{NaHCO}_{3}-\mathrm{P}_{\mathrm{O}}$ transitioned to negative effect, which indicates that the interaction of soil with biochar can cause changes in soil $\mathrm{NaHCO}_{3}-\mathrm{P}_{\mathrm{o}}$ content, moving from an increase to a significant decrease (Table 2, Figure 1). The significant decrease in $\mathrm{NaHCO}_{3}-\mathrm{P}_{\mathrm{O}}$ content was conflicting with the high $\mathrm{C}: \mathrm{P}$ ratios of biochar, suggesting that net $\mathrm{P}$ immobilization occurred when

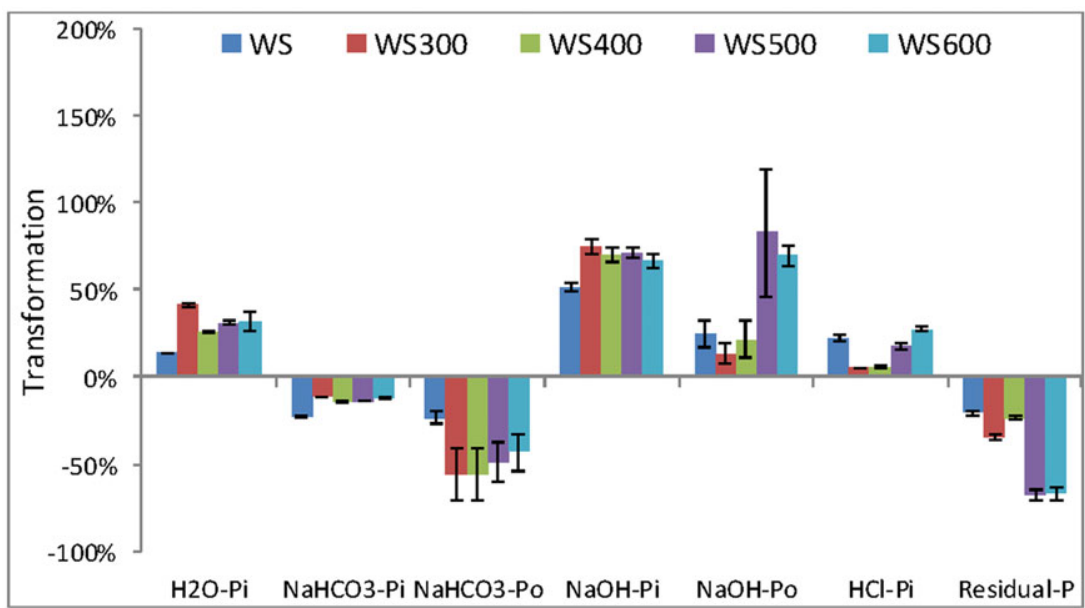

FIGURE 2 The transformations of $\mathrm{P}$ in a Haplic Luvisol at 30 incubation days with different biochars (data in the figure indicate means of three replicates, $\pm S D$ ) [Colour figure can be viewed at wileyonlinelibrary.com] 
FIGURE 3 The transformations of $P$ in a Calcaric-Fluvisol at four incubation days with different biochars (data in the figure indicate means of three replicates, $\pm S D$ ) [Colour figure can be viewed at wileyonlinelibrary.com]
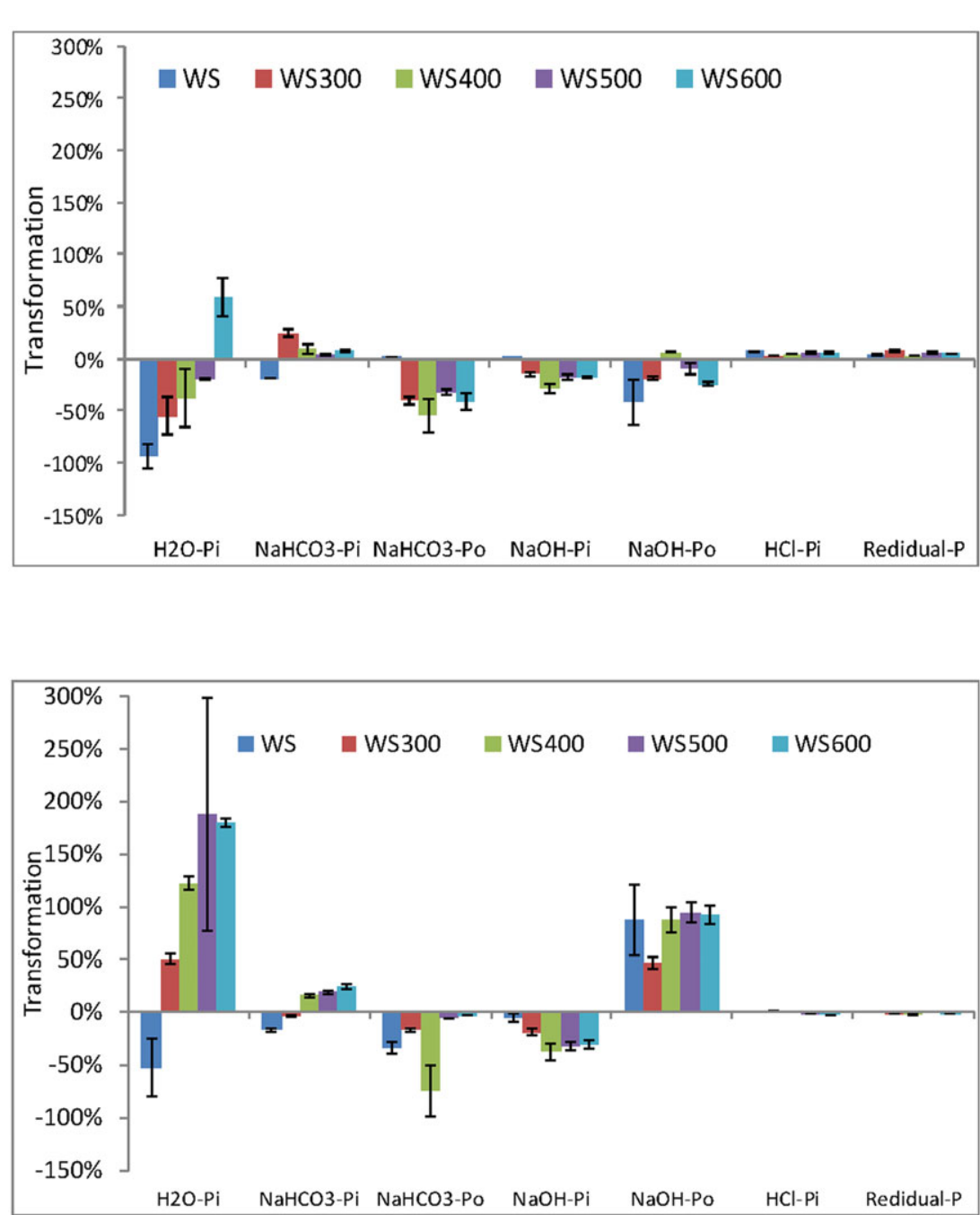

$\mathrm{H} 2 \mathrm{O}-\mathrm{Pi} \quad \mathrm{NaHCO} 3-\mathrm{Pi} \quad \mathrm{NaHCO} 3-\mathrm{Po} \quad \mathrm{NaOH}-\mathrm{Pi} \quad \mathrm{NaOH}-\mathrm{Po} \quad \mathrm{HCl}-\mathrm{Pi}$ Redidual-P
FIGURE 4 The transformations of $\mathrm{P}$ in a Calcaric-Fluvisol at 30 incubation days with different biochars (data in the figure indicate means of three replicates, $\pm S D$ ) [Colour figure can be viewed at wileyonlinelibrary.com] biochar was incorporated into soil. Moreover, Zhai et al. (2014) reported that biochar application significantly reduced acid phosphomonoesterase activity in Red earth soil, indicating the reduction of mineralization of organic $P$. We suggest that the decrease in $\mathrm{NaHCO}_{3}-\mathrm{P}_{\mathrm{o}}$ concentration and the increase in $\mathrm{NaOH}-\mathrm{P}_{\mathrm{i}}$ concentration over time suggest the transformation of labile organic $\mathrm{P}$ into nonlabile inorganic or organic $\mathrm{P}$ by $\mathrm{P}$ sorption or fixation (Alamgir \& Marschner, 2016; Anderson et al., 2011; Breton, Crosaz, \& Rey, 2016). In general, biochar application in Haplic Luvisol increased $\mathrm{P}$ transformation and thereby $\mathrm{P}$ availability by increasing soil microbial activity and by reducing soil acidity or increasing soil CEC.

\section{2 | P transformation induced by biochar addition into a Calcaric-Fluvisol}

Unlike Haplic Luvisol, biochar addition exhibited a negative effect on most forms of $\mathrm{P}$ (except $\mathrm{HCl}-\mathrm{P}_{\mathrm{i}}$ and residual-P) in Calcaric-Fluvisol (Figures 3 and 4), indicating that the reaction between CalcaricFluvisol and biochar converted available P. Adding biochar to the Calcaric-Fluvisol may lead to increase in $\mathrm{pH}$, and excessively high $\mathrm{pH}$ may cause the reactive $\mathrm{P}$ soil to be precipitated or adsorbed $(\mathrm{Xu}$, Wei, Sun, Shao, \& Chang, 2013). Also, unlike Haplic Luvisol, CalcaricFluvisol showed slightly increased $\mathrm{NaHCO}_{3}-\mathrm{P}_{\mathrm{i}}$ levels at Day 4 , and a negative effect was observed for $\mathrm{NaHCO}_{3}-\mathrm{P}_{\mathrm{o}}$ and $\mathrm{NaOH}-\mathrm{P}_{\mathrm{i}}$ and
$\mathrm{NaOH}-\mathrm{P}_{\mathrm{o}}$, indicating that the addition of biochar does not significantly stimulate the microbial activity in Calcaric-Fluvisol. The insignificant increase in available soil $\mathrm{P}$ was probably related to the relatively high $\mathrm{pH}$ of the soil studied (Murphy \& Stevens, 2010; Yazdanpanah, Mahmoodabadi, \& Cerdà, 2016). At Day 30, biochar exhibited a positive effect on soil $\mathrm{NaOH}-\mathrm{P}_{\mathrm{o}}$ levels, suggesting an increase in the microbial activity of soil (Zhai et al., 2014). In general, the application of biochar to Calcaric-Fluvisol is not conducive to the transformation or enhancement of the availability of soil P.

In order to elucidate the mechanisms of $\mathrm{P}$ transformations affected by biochar application, the soil microbial communities, especially phosphate-solubilizing bacteria communities, deserve further study. In addition, the interaction effect between biochar and $\mathrm{P}$ fertilizer on $\mathrm{P}$ transformations in soil needs further investigation.

\section{5 | CONCLUSION}

The biochar application in Haplic Luvisol and Calcaric-Fluvisol had different effects on $\mathrm{P}$ fractions in the soils. For the Haplic Luvisol, biochar showed a positive effect on most forms of $\mathrm{P}$ (except $\mathrm{NaHCO}_{3}-\mathrm{P}$ and residual-P). Over incubation time, content of $\mathrm{NaHCO}_{3}-\mathrm{P}_{\mathrm{o}}$ was subject to a negative rather than positive effect, suggesting the transformation of labile organic $\mathrm{P}$ into nonlabile inorganic or organic $\mathrm{P}$ by $\mathrm{P}$ 
sorption or fixation. For the Calcaric-Fluvisol, biochar exhibited negative effects on various forms of $\mathrm{P}$. In terms of the availability of soil $\mathrm{P}$, biochar should be used mainly for the amendment of acidic soil such as Haplic Luvisol.

\section{ACKNOWLEDGMENTS}

This research was supported by the National Natural Science Foundation of China (41573120 and 41501309), Agricultural Independent Innovation of Jiangsu Province (CX (15)1005), and Shuangchuang Talent Plan of Jiangsu Province, China the Key Deployment Project of Chinese Academy of Sciences (KFZD-SW-112) and the Science and Technology Service Network Initiative (KFJ-STS-ZDTP-023). Special thanks to Professor C. H. Gu from the Department of Geological and Environmental Sciences, Appalachian State University, USA, for the language improvement.

\section{CONFLICT OF INTEREST}

There is no conflict of interest regarding the paper.

\section{AUTHOR CONTRIBUTIONS}

G. X. and H. S. designed the experiment. G. X., J. S., and Y. Z. performed the experiment. G. X. and H. S. wrote and revised the paper.

\section{ORCID}

Hongbo Shao (i) http://orcid.org/0000-0002-3921-5485

\section{REFERENCES}

Ahmad, M., Rajapaksha, A. U., Lim, J. E., Zhang, M., Bolan, N., Mohan, D., Ok, Y. S. 2014. Biochar as a sorbent for contaminant management in soil and water: A review. Chemosphere, 99: 19-23. https:// doi:10.1016/j.chemosphere.2013.10.071

Alamgir, M., \& Marschner, P. (2013). Short-term effects of application of different rates of inorganic $\mathrm{P}$ and residue $\mathrm{P}$ on soil $\mathrm{P}$ pools and wheat growth. Journal of Plant Nutrition and Soil Science, 176, 696-702. https://doi.org/10.1002/jpln. 201200290

Alamgir, M., \& Marschner, P. (2016). Changes in P pools over three months in two soils amended with legume residues. Journal of Soil Science and Plant Nutrition, 16, 76-87. https://doi.org/10.4067/S0718-951620 16005000006

Anderson, C. R., Condron, L. M., Clough, T. J., Fiers, M., Stewart, A., \& Hill RASherlock, R. R. (2011). Biochar induced soil microbial community change: implications for biogeochemical cycling of carbon, nitrogen and phosphorus. Pedobiologia, 54, 309-320. https://doi.org/10.1016/ j.pedobi. 2011.07.005

Angst, T. E., \& Sohi, S. P. (2013). Establishing release dynamics for plant nutrients from biochar. GCB Bioenergy, 5, 221-226. https://doi.org/ 10.1111/gcbb. 12023

Biederman, L. A., \& Harpole, W. S. (2013). Biochar and its effects on plant productivity and nutrient cycling: a meta-analysis. GCB Bioenergy, 5, 202-214. https://doi.org/10.1111/gcbb. 12037

Breton, V., Crosaz, Y., \& Rey, F. (2016). Effects of wood chip amendments on the revegetation performance of plant species on eroded marly terrains in a Mediterranean mountainous climate (Southern Alps, France). Solid Earth, 7, 599-610. https://doi.org/10.5194/se-7-599-2016

DeLuca, T. H., MacKenzie, M. D., \& Gundale, M. J. (2009). Biochar effects on soil nutrient transformations. Biochar for Environmental Management: Science and Technology, 251-270.

Elser, J., \& Bennett, E. (2011). Phosphorus cycle: A broken biogeochemical cycle. Nature, 478, 29-31. https://doi.org/10.1038/478029a
Farrell, M., Macdonald, L. M., Butler, G., Chirino-Valle, I., \& Condron, L. M. (2014). Biochar and fertiliser applications influence phosphorus fractionation and wheat yield. Biology and Fertility of Soils, 50, 169-178. https://doi.org/10.1007/s00374-013-0845-z

Guo, M., He, Z., \& Uchimiya, S. M. (2016). Agricultural and environmental application of biochar: Advances and barriers (Vol. 63). ( pp. 1-11). Madison, WI 53711, USA: SSSA Special Publication.

Hammer, E. C., Balogh-Brunstad, Z., Jakobsen, I., Olsson, P. A., Stipp, S. L., \& Rillig, M. C. (2014). A mycorrhizal fungus grows on biochar and captures phosphorus from its surfaces. Soil Biology and Biochemistry, 77, 252-260. https://doi.org/10.1016/j.soilbio. 2014.06.012

He, H., Qian, T.-T., Liu, W.-J., Jiang, H., \& Yu, H.-Q. (2014). Biological and chemical phosphorus solubilization from pyrolytical biochar in aqueous solution. Chemosphere, 113, 175-181. https://doi.org/10.1016/j. chemosphere. 2014.05.039

He, Z., Fortuna, A., Senwo, Z. N., Tazisong, I. A., Honeycutt, C. W., \& Griffi, T. S. (2006). Hydrochloric fractions in Hedley fractionation may contain inorganic and organic phosphates. Soil Science Society of America Journal, 70, 893-899. https://doi.org/10.2136/sssaj2005.0152

Jeffery, S., Abalos, D., Prodana, M., Bastos, A., van Groenigen, J. W., Hungate, B., \& Verheijen, F. (2017). Biochar boosts tropical but not temperate crop yields. Environmental Research Letters., 12(5). 053001. https://doi.org/10.1088/1748-9326/aa67bd

Jiang, J., Yuan, M., Xu, R., \& Bish, D. L. (2015). Mobilization of phosphate in variable-charge soils amended with biochars derived from crop straws. Soil and Tillage Research, 146, 139-147. https://doi.org/10.1016/j.still. 2014.10.009

Kloss, S., Zehetner, F., Dellantonio, A., Hamid, R., Ottner, F., Liedtke, V., ... Soja, G. (2012). Characterization of slow pyrolysis biochars: Effects of feedstocks and pyrolysis temperature on biochar properties. Journal of Environmental Quality, 41, 990-1000. https://doi.org/10.2134/ jeq2011.0070

Liang, B., Lehmann, J., Solomon, D., Kinyangi, J., Grossman, J., O'Neill, B., ... Neves, E. G. (2006). Black carbon increases cation exchange capacity in soils. Soil Science Society of America Journal., 70, 1719-1730. https:// doi.org/10.2136/sssaj2005.0383.

Makoto, K., Shibata, H., Kim, Y., Satomura, T., Takagi, K., Nomura, M., ... Koike, T. (2012). Contribution of charcoal to short-term nutrient dynamics after surface fire in the humus layer of a dwarf bamboo-dominated forest. Biology and Fertility of Soils, 48, 569-577. https://doi.org/ 10.1007/s00374-011-0657-y

Mao, W., Kang, S., Wan, Y., Sun, Y., Li, X., \& Wang, Y. (2016). Yellow river sediment as a soil amendment for amelioration of saline land in the Yellow River delta. Land Degradation \& Development, 27, 1595-1602. https://doi.org/10.1002/ldr.\%202323.

Morales, M., Comerford, N., Guerrini, I. A., Falcão, N., \& Reeves, J. (2013). Sorption and desorption of phosphate on biochar and biochar-soil mixtures. Soil Use and Management, 29, 306-314. https://doi.org/ 10.1111/sum. 12047

Murphy, J., \& Riley, J. P. (1962). A modified single solution method for the determination of phosphate in natural waters. Analytica Chimica Acta, 27, 31-36. https://doi.org/10.1016/S0003-2670 (00)88444-5

Murphy, P. N., \& Stevens, R. (2010). Lime and gypsum as source measures to decrease phosphorus loss from soils to water. Water, Air, \& Soil Pollution, 212, 101-111. https://doi.org/10.1007/s11270-010-0325-0

Novak, J. M., Lima, I., Baoshan, X., Gaskin, J. W., Steiner, C., Das, K. C., ... Schomberg, H. (2009). Characterization of designer biochar produced at different temperatures and their effects on a loamy sand. Annals of Environmental Science, 3, 195-206.

Parvage, M. M., Ulén, B., Eriksson, J., Strock, J., \& Kirchmann, H. (2013). Phosphorus availability in soils amended with wheat residue char. Biology and Fertility of Soils, 49, 245-250. https://doi.org/10.1007/ s00374-012-0746-6

Schulz, H., \& Glaser, B. (2012). Effects of biochar compared to organic and inorganic fertilizers on soil quality and plant growth in a greenhouse 
experiment. Journal of Plant Nutrition and Soil Science, 175, 410-422. https://doi.org/10.1002/jpln.201100143

Scott, H., Ponsonby, D., \& Atkinson, C. (2014). Biochar: An improver of nutrient and soil water availability-What is the evidence? $C A B$ Reviews: Perspectives in Agriculture, Veterinary Science, Nutrition and Natural Resources, 9, 1-19. https://doi.org/10.1079/ PAVSNNR20149019

Shi, X., Yu, D., Xu, S., Warner, E., Wang, H., Sun, W., ... Gong, Z. (2010). Cross-reference for relating genetic soil classification of China with WRB at different scales. Geoderma, 155, 344-350. https://doi.org/ 10.1016/j.geoderma.2009.12.017

Singh, B., Singh, B. P., \& Cowie, A. L. (2010). Characterisation and evaluation of biochars for their application as a soil amendment. Soil Research, 48, 516-525.

Singh, R., Babu, J. N., Kumar, R., Srivastava, P., Singh, P., \& Raghubanshi, A. S. (2015). Multifaceted application of crop residue biochar as a tool for sustainable agriculture: An ecological perspective. Ecological Engineering, 77, 324-347. https://doi.org/10.1016/j.ecoleng.2015.01.011

Smith, P., \& Gregory, P. J. (2013). Climate change and sustainable food production. Proceedings of the Nutrition Society., 72(1), 21-28. https://doi. org/10.1017/S0029665112002832

Srivastava, P. K., Gupta, M., Shikha, N. S., \& Tewari, S. K. (2016). Amelioration of sodic soil for wheat cultivation using bioaugmented organic soil amendment. Land Degradation and Development, 27, 1245-1254. https://doi.org/10.1002/ldr.\%202292.

Tiessen, H., \& Moir, J. (1993). Characterization of available P by sequential extraction. Soil Sampling and Methods of Analysis, 7, 5-229.

Vanek, S. J., \& Lehmann, J. (2015). Phosphorus availability to beans via interactions between mycorrhizas and biochar. Plant and Soil, 395, 105-123. https://doi.org/10.1007/s11104-014-2246-y

Wang, Y., Fang, S., Chang, S. X., \& Tian, Y. (2014). Non-additive effects of litter-mixing on soil carbon dioxide efflux from poplar-based agroforestry systems in the warm temperate region of China. Agroforestry Systems, 88, 193-203. https://doi.org/10.1007/s10457-013-9665-2
Xu, G., Wei, L., Sun, J., Shao, H., \& Chang, S. X. (2013). What is more important for enhancing nutrient bioavailability with biochar application into a sandy soil: Direct or indirect mechanism? Ecological Engineering, 52, 119-124. https://doi.org/10.1016/j.ecoleng. 2012.12.091

Xu, G., Sun, J., Shao, H., \& Chang, S. X. (2014). Biochar had effects on phosphorus sorption and desorption in three soils with differing acidity. Ecological Engineering, 62, 54-60. https://doi.org/10.1016/j.ecoleng. 2013.10.027

Xu, G., Zhang, Y., Shao, H., \& Sun, J. (2016). Pyrolysis temperature affects phosphorus transformation in biochar: Chemical fractionation and ${ }^{31} \mathrm{P}$ NMR analysis. Science of the Total Environment, 569, 65-72. https:// doi.org/10.1016/j.scitotenv.2016.06.081

Yazdanpanah, N., Mahmoodabadi, M., \& Cerdà, A. (2016). The impact of organic amendments on soil hydrology, structure and microbial respiration in semiarid lands. Geoderma, 266, 58-65. https://doi.org/10.1016/ j.geoderma. 2015.11.032

Zhai, L., CaiJi, Z., Liu, J., Wang, H., Ren, T., Gai, X., ... Liu, H. (2014). Shortterm effects of maize residue biochar on phosphorus availability in two soils with different phosphorus sorption capacities. Biology and Fertility of Soils, 51, 1-10. https://doi.org/10.1007/s00374-014-0954-3

Zhang, X., Luo, Y., Müller, K., Chen, J., Lin, Q., Xu, J., ... Wang, H. (2016). Research and application of biochar in China. In M. Guo, Z. He, \& M. Uchimiya (Eds.), Agricultural and environmental applications of biochar: Advances and barriers. Madison, WI: SSSA Spec. Publ. 63. SSSA. https://doi.org/10.2136/sssaspecpub63.2014.0049

How to cite this article: Xu G, Shao H, Zhang Y, Junna S. Nonadditive effects of biochar amendments on soil phosphorus fractions in two contrasting soils. Land Degrad Dev. 2018;29:2720-2727. https://doi.org/10.1002/ldr.3029 